\title{
Host phylogeny matters: Examining sources of variation in infection risk by blood parasites across a tropical montane bird community in India
}

\author{
Pooja Gupta ${ }^{1,2,3^{*}}$ (D) C. K. Vishnudas ${ }^{4}$, V. V. Robin ${ }^{4}$ (ib and Guha Dharmarajan ${ }^{1,3}$ (D)
}

\begin{abstract}
Background: Identifying patterns and drivers of infection risk among host communities is crucial to elucidate disease dynamics and predict infectious disease risk in wildlife populations. Blood parasites of the genera Plasmodium and Haemoproteus are a diverse group of vector-borne protozoan parasites that affect bird populations globally. Despite their widespread distribution and exceptional diversity, factors underlying haemosporidian infection risk in wild bird communities remain poorly understood. While some studies have examined variation in avian haemosporidian risk, researchers have primarily focused on host ecological traits without considering host phylogenetic relationships. In this study, we employ a phylogenetically informed approach to examine the association between host ecological traits and haemosporidian infection risk in endemic bird communities in the Western Ghats Sky Islands.

Methods: We used parasite sequence data based on partial mitochondrial cytochrome $b$ gene, that was amplified from genomic DNA extracted from 1177 birds (28 species) across the Western Ghats to assess infection of birds with haemosporidian parasites. We employed a Bayesian phylogenetic mixed effect modelling approach to test whether haemosporidian infection risk was affected by seven species-specific and four individual-level ecological predictors. We also examined the effect of host phylogenetic relationships on the observed patterns of variation in haemosporidian infection risk by estimating phylogenetic signal.
\end{abstract}

Results: Our study shows that host ecological traits and host phylogeny differentially influence infection risk by Plasmodium (generalist parasite) and Haemoproteus (specialist parasite). For Plasmodium, we found that sociality, sexual dimorphism and foraging strata were important ecological predictors. For Haemoproteus, patterns of infection risk among host species were associated with sociality, species elevation and individual body condition. Interestingly, variance in infection risk explained by host phylogeny was higher for Haemoproteus parasites compared to Plasmodium.

Conclusions: Our study highlights that while host ecological traits promoting parasite exposure and host susceptibility are important determinants of infection risk, host phylogeny also contributes substantially to predicting patterns of haemosporidian infection risk in multi-host communities. Importantly, infection risk is driven by joint contributions of host ecology and host phylogeny and studying these effects together could increase our ability to better understand the drivers of infection risk and predict future disease threats.

\footnotetext{
*Correspondence: biopooja@gmail.com

1 Savannah River Ecology Laboratory, University of Georgia, Aiken, SC, USA

Full list of author information is available at the end of the article
}

(c) The Author(s) 2020, corrected publication 2021. This article is licensed under a Creative Commons Attribution 4.0 International License, which permits use, sharing, adaptation, distribution and reproduction in any medium or format, as long as you give appropriate credit to the original author(s) and the source, provide a link to the Creative Commons licence, and indicate if changes were made. The images or other third party material in this article are included in the article's Creative Commons licence, unless indicated otherwise in a credit line to the material. If material is not included in the article's Creative Commons licence and your intended use is not permitted by statutory regulation or exceeds the permitted use, you will need to obtain permission directly from the copyright holder. To view a copy of this licence, visit http://creativecommons.org/licenses/by/4.0/. The Creative Commons Public Domain Dedication waiver (http://creativeco mmons.org/publicdomain/zero/1.0/) applies to the data made available in this article, unless otherwise stated in a credit line to the data. 
Keywords: Avian haemosporidians, Plasmodium, Haemoproteus, Ecological traits, Host phylogeny, Infection dynamics, Western Ghats, India

\section{Background}

Identifying factors that determine the variation in infection risk in natural populations is of fundamental importance for understanding the ecology and evolution of host-parasite interactions, predicting infection risk and biological conservation $[1,2]$. In multi-host, multi-parasite systems, a myriad of factors operating at the individual- and species-level can affect the probability of parasite exposure and subsequent infection across host species [3-6]. At the species level, variation in infection risk can occur because of differences in host life history, behavior and environment that underpin patterns of parasite exposure [7-10]. At the individual host level, hosts can vary in infection risk owing to differences in exposure to parasites and host susceptibility. In the case of vector-borne diseases, hosts exposure to parasites can increase via increase in frequency of encounter with dipteran vectors that can influence disease transmission [11]. For instance, host exposure can be impacted by geographical factors that affect vector abundance (e.g. elevation [12]) or host ecological traits that affect exposure risk such as foraging/nest height $[13,14]$ or sociality $[10$, $15,16]$. Additionally, some species-specific traits associated with disease susceptibility (e.g. sexual dimorphism) or individual-level traits associated with fitness (e.g. fluctuating asymmetry $[17,18]$ and body condition $[19,20])$ could be important predictors of infection risk in natural communities.

Avian haemosporidian parasites (Apicomplexa: Haemosporida) of the genera Plasmodium, Haemoproteus (including Parahaemoproteus) are protozoan blood parasites that affect bird populations globally [21]. Avian haemosporidians (commonly referred to as avian malaria parasites) are an exceptionally diverse group of parasites, with over 2500 parasite genetic lineages [22]. These parasites are transmitted by arthropod vectors, with Plasmodium being transmitted by culicid mosquitoes, and Haemoproteus by ceratopogonid biting midges and hippoboscid louse flies [21,23]. Avian haemosporidians can impose strong selective pressures on bird hosts as they are known to reduce longevity [24], host fitness [25, 26], individual host condition [27] and have led to severe population declines [28-31]. Previous research has revealed that avian haemosporidian parasites vary widely in their host range, with Plasmodium lineages often being generalists infecting a broad range of host species and Haemoproteus lineages often being specialists infecting one or few closely related host species [32-34] but this pattern is not universal $[35,36]$. Plasmodium and Haemoproteus parasites are also known to exhibit eco-evolutionary differences, with community structure of Plasmodium generally affected by abiotic factors such as spatial proximity and Haemoproteus, primarily affected by biotic factors such as host phylogeny and host ecology [32, 37, 38] but see $[39,40]$. Given the widespread distribution, diversity and pronounced eco-evolutionary differences between Plasmodium and Haemoproteus, variation in parasite prevalence for the two parasite genera could be affected by different ecological and evolutionary factors in multihost communities.

Several studies have attempted to identify ecological factors that can predict haemosporidian infection risk in avian communities, but offer mixed support, in part, owing to the limited exploration of concomitant factors simultaneously across entire host assemblages and across both parasite genera or challenges associated with understanding complex interactions operating across different scales (e.g. within and between species). For instance, specific habitat and temperature requirements of different haemosporidian vectors (e.g. mosquitoes, biting midges) and parasites may limit their distribution on an elevational gradient and across habitat types [12, 41]. While some studies support higher prevalence of Haemoproteus at high elevations and high prevalence of Plasmodium at lower elevations $[42,43]$ others present contrasting patterns, with high prevalence of Haemoproteus and Plasmodium at mid-elevations [44] and no effect of elevation for Haemoproteus and Plasmodium parasites [14].

Roosting and foraging stratum of host species may increase the probability of hosts encountering vectors thereby promoting parasite transmission. It has been hypothesized that social aggregations attract vectors, and this could lead to higher prevalence of avian haemosporidians in social species $[16,45]$. Furthermore, vertical stratification in arthropod vectors could result in variation in avian haemosporidian infection risk due to differences in abundance of vectors in the canopy compared to the ground level [46-48]. Other species ecological traits such as host specialization (e.g. habitat or elevational specialization) could also lead to differential exposure to vectors/ parasites. Generalists species, spanning a wider elevational range, may encounter more vectors or a greater diversity of habitats compared to elevational specialists, leading to higher parasite prevalence in generalists than specialists. Furthermore, previous studies suggest host species that 
exhibit sexually dimorphic traits (e.g. plumage brightness) have likely been exposed to higher levels of parasitism because parasite pressure is a strong driver of sexual selection on these traits $[49,50]$. Thus, species that are more susceptible to parasite infections likely exhibit higher levels of sexual dimorphism [49].

At the individual level, previous studies suggest that birds with higher average body size tend to have higher infection probability as larger body size will likely provide more surface area for vector feeding and emit higher quantity of olfactory cues (e.g. $\left.\mathrm{CO}_{2}\right)$, thereby attracting more vectors $[14,51]$. Host body condition can also affect the likelihood of infection due to differences in individual susceptibility. A negative association between body condition and parasitism is generally expected, either due to reduced immunocompetence in birds with poor body condition and increased susceptibility or the direct effects of parasitism on the fitness of individuals, leading to poor body condition $[4,20]$. Furthermore, fluctuating asymmetry (defined as small, random deviations from symmetry of bilateral symmetrical traits [52]) could be an important predictor for avian haemosporidian infection. The positive association between fluctuating asymmetry and parasitism is relatively common in natural populations [17, 18], and this association could exist either because parasitism (as a form of developmental stress) can directly increase levels of fluctuating asymmetry, or because individuals with high fluctuating asymmetry have low immunity.

Although several factors have been proposed to explain variation in parasite prevalence and infection risk among individuals and host species [13, 14, 43, 48, 51, 53], it remains unclear whether the role of host ecological traits are generally predictable or whether they are idiosyncratic across hosts, parasites and environmental conditions and context-dependent. Additionally, evolutionary history of host species can confound the relationship between ecological traits and parasite infection risk as closely related species are more likely to share risk factors compared to non-related host species. Despite this, surprisingly few studies have taken evolutionary history of the hosts into account (e.g. $[48,54])$ and thus, the importance of host evolutionary history in predicting infection risk is less well understood.

The Tropical Sky Island bird community in the Western Ghats mountains, located parallel to the southern coast of India (Fig. 1), offers an excellent model system to elucidate the factors influencing variation in avian haemosporidian infection risk. The Western Ghats are a global biodiversity hotspot [55], and the high endemic bird diversity in the Western Ghats [56] provides opportunities for native parasites to exploit a wide variety of hosts, allowing us to test how host ecology impacts parasite infection risk. Additionally, the landscape is threatened by anthropogenic habitat fragmentation and landuse changes; and the potential negative impact of avian malaria in this biodiversity hotspot makes the identification of factors associated with increased infection risk an important step for conservation [57].

Sky Islands are isolated mountain-top habitats surrounded by dramatically different lowland habitats. The replicated arrangement of geographically discrete, identical habitats provides an ideal natural laboratory to explore ecological dynamics underlying avian haemosporidian infection risk. The Western Ghats mountains are interrupted by three major bio-geographical breaks, the Chaliyar River valley (2-3 km wide), the deepest Palghat Gap (40 km wide) and the Shencottah Gap (10 km wide), resulting in genetic differentiation and speciation across a range of taxa [58-60]. Such patterns of genetic differentiation in hosts could impact the spatial distribution of parasite populations harboring these bird hosts. Within each Western Ghats mountain, Sky Islands hosts unique natural matrix of wet, montane evergreen forests and grasslands, locally known as Sholas, above 1400 m (henceforth Shola Sky Islands), while low elevations harbor drier habitats. High habitat heterogeneity and climatic conditions due to its elevational gradient have led to disproportionately high host species diversity in the Shola Sky Islands, comprising of host species having different habitat specialization, life history strategies and elevational distribution. For example, montane specialists are restricted to high elevations and generalists are distributed widely from high to low elevations. While montane specialists have likely been historically protected from avian malaria because low temperatures at high elevations leads to low vector abundance [61] or poor parasite development [12], this scenario might be changing as global warming progresses [41, 62]. Thus, Western Ghats Sky Islands offer a valuable system in which to investigate infection dynamics, especially in the light of possible climate change driven extinctions in the landscape (e.g. Robin et al. [63]).

In this study, we first examine the species- and individual-level ecological factors that influence variation in avian haemosporidian prevalence and thus avian haemosporidian infection risk in the Western Ghats. Next, we examine if these effects differ across the two parasite genera, Plasmodium and Haemoproteus. Secondly, we test the effect of host evolutionary history in explaining variation in avian haemosporidian infection risk not explained by host ecological factors. As mentioned earlier, several studies suggest that Plasmodium is a generalist parasite and Haemoproteus is a relatively specialist parasite [3234], thus we expect that the effects of ecological factors will vary for Plasmodium and Haemoproteus in addition 


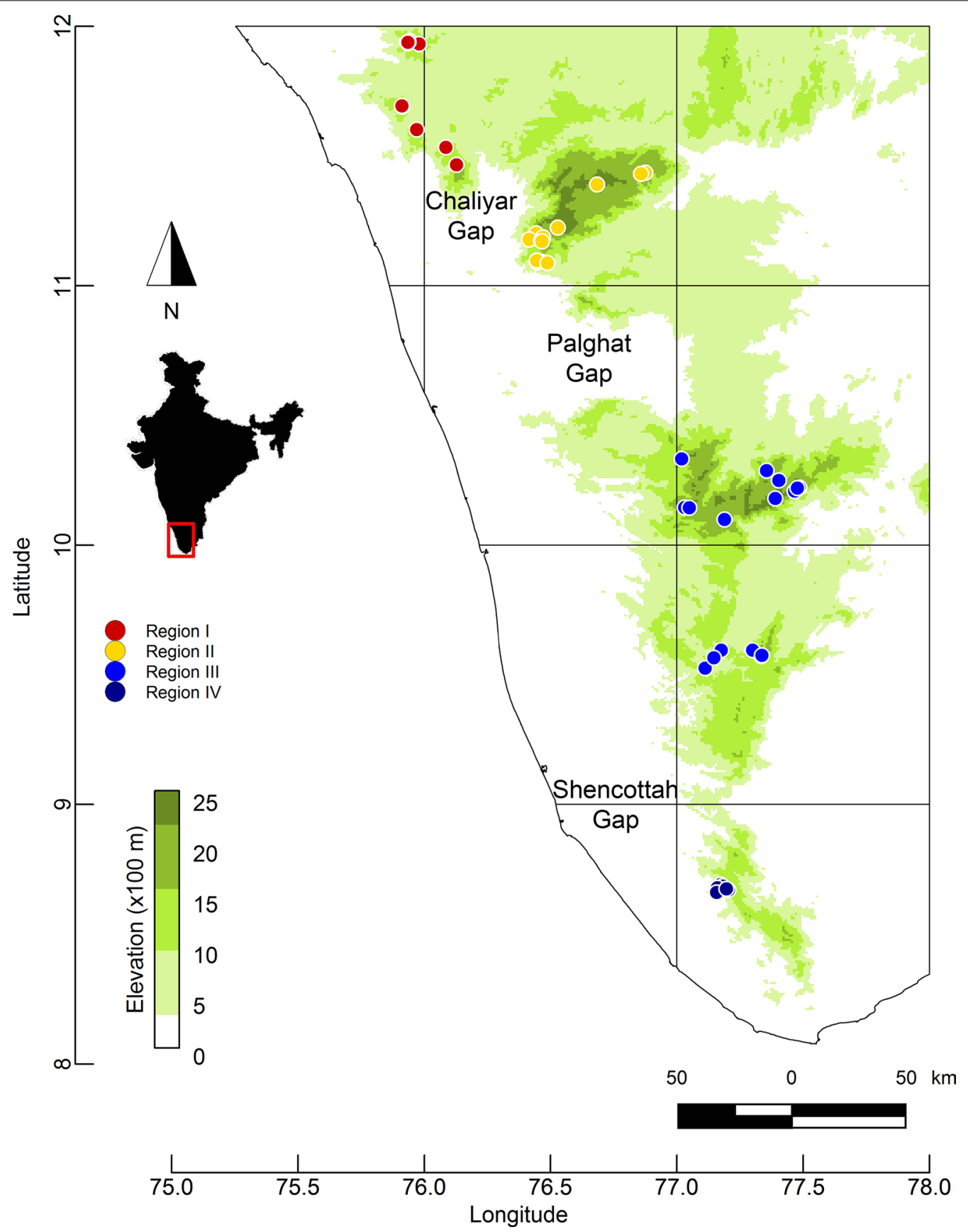

Fig. 1 Map of the Western Ghats including locations of sampling sites (filled circles) in four geographical regions: I (Bababudan and Banasura hills), II (Nilgiri hills), III (Anamalai-Palni-Highwavies hills), IV (Ashambu hills), corresponding to the major Sky Island group. Underlying elevation gradient in the Western Ghats is also depicted, with Shola Sky Islands located above 1400 m.a.s.l

to their intrinsic differences in parasite biology and vector specificity. At the species-level, we expect that: (i) species that have a lower minimum elevation will have higher Plasmodium prevalence whereas species with a higher minimum elevation will have higher Haemoproteus prevalence (Fig. 2); (ii) species foraging at higher forest strata will have lower Plasmodium prevalence and higher Haemoproteus prevalence compared to species foraging at the ground level (Fig. 2); (iii) social living species and species with sexually dimorphic traits will likely exhibit higher parasite prevalence of both parasites (Fig. 2). Furthermore, at the individual-level, we expect: 
(iv) infection risk would increase with increase in body size and fluctuating asymmetry (Fig. 2); and (v) birds with better body condition will likely be less infected by both parasites compared to birds with poorer body condition (Fig. 2).

\section{Methods}

\section{Study area and collection of parasite data}

We used bird data and parasite genetic data collected as part of an earlier study, see details in Gupta et al. [32]. Briefly, birds were captured using mist-nets at 52 localities across four major Sky Island groups, separated by three biogeographic barriers, spanning $600 \mathrm{~km}$ in the southern Western Ghats mountain range during 20112013 (Fig. 1). Blood samples $(50-100 \mu \mathrm{l})$ were collected from the ulnar vein of the bird with a heparinized microhematocrit capillary tube and immediately stored in blood lysis buffer. Avian haemosporidian infection was identified by amplifying parasite's partial mitochondrial cytochrome $b$ gene (478 bp) [64]. Positive infections were sequenced, and paired DNA sequences were aligned in GeNeIOUS 9.1.5 [65]. Unique haemosporidian lineages were identified by comparing parasite sequences with publicly available sequences in NCBI and in the MalAvi database [22].

\section{Ecological trait data}

We collected data on host ecological traits based on the current understanding of vectors transmitting avian haemosporidians and included traits that increase hosts' exposure and/or host susceptibility to parasitism. Data on ecological traits of host species was collected from previous field observations by CKV and VVR and additionally sourced from the Wilman dataset [66]. Our dataset included seven species-specific variables: foraging strata (high/low), roosting behavior (social/non-social), host habitat type (forest/grassland), elevational range (specialist/generalist), genetic connectivity (breaks/no breaks), sexual dimorphism (yes/ no) as categorical variables and minimum species elevation as a covariate (details in Additional file 1: Tables S1, S2). Briefly, birds were classified into two categories based on their foraging strata: low (ground foraging) and high (understory to mid-level foraging) based on Somasundaram et al. [67] and Wilman et al. [66], with the former being given precedence as it reported data specific to the Western Ghats. Species roosting behavior was categorized into social and non-social based on field observations by CKV and VVR. Host habitat type was based on species habitat preferences: forest (species preferring evergreen, semi-evergreen, moist-deciduous, dry-deciduous, scrub habitat) or grassland (open country, grassland) based on Ali \& Ripley [68] and field observations by CKV and VVR. Species elevational range was classified into two categories: specialists (species restricted to high-elevations, occurring above $1400 \mathrm{~m}$ ) and generalists (species having a wider distribution ranging from low to high elevations) as assessed in an earlier study [58]. Genetic connectivity was classified as: breaks/no breaks (species with evidence of genetic divergence or no evidence of genetic divergence due to the biogeographical gaps, respectively) based on Robin et al. [58]. Sexual dimorphism was classified into two categories: yes/no (species with differences in plumage between sexes or no plumage differences between sexes, respectively) based on Ali \& Ripley [68]. We used bird distribution data to estimate the minimum elevational distribution extent of the bird species (details in Additional file 1: Table S2).

At the level of individual host, the ecological trait data consisted of four variables associated with body size, fluctuating asymmetry (FA) and body condition. The body size variables included tarsus and wing measurements (details in Additional file 1: Table S2). We calculated a measure of fluctuating asymmetry with respect to tarsus $\left(\mathrm{FA}_{\text {Tarsus }}\right)$ as per Van Dongen [69]. We also estimated individual body condition, a commonly used proxy of infection-induced fitness cost [20], based on scaled mass index $\hat{M}$, as proposed by Peig \& Green [70], which accounts for covariance between body size and body mass components. The condition score was calculated by standardizing body mass at a fixed value of a linear body measurement based on the scaling relationship between mass and length. We used body weight as the mass measurement and wing length measurement as the length variable because average wing length was most strongly correlated with body weight on a log-log scale (Pearson correlation, $r=0.80, P<0.001$, details in Additional file 1: Table S2). All individual measurement variables were standardized by a z-transform within each species (i.e. a unit increase in the measurement indicates one standard deviation increase over the mean value for the species).

\section{Statistical analyses}

We built Bayesian phylogenetic mixed models (BPMM) to assess the association between infection risk and host ecological and morphometric traits using the R-package MCMCglmm [71]. We used BPMM as it allowed us to control for statistical non-independence of trait data due to host phylogenetic relationships [72]. We modeled host infection status as a binary response variable ( 0 for uninfected, 1 for infected) with a logit link, for Plasmodium and Haemoproteus, and different species- and individuallevel ecological traits as predictor variables. To account for shared ancestry between host species, we fitted a 


\section{Species level factors}
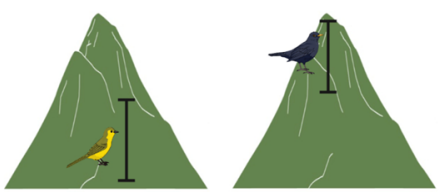

A. Low elevation B. High elevation

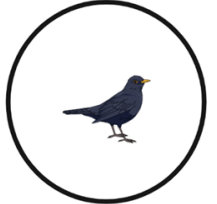

A. Non Social

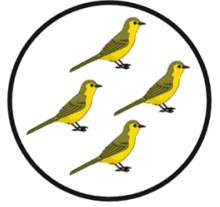

B. Social
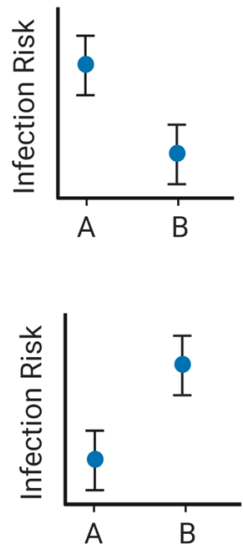
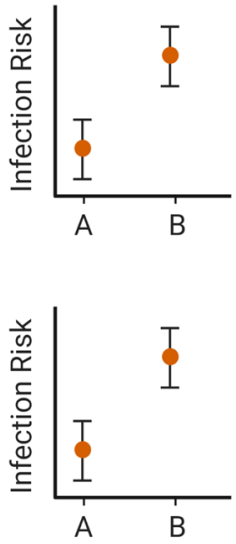

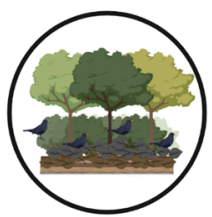

A. Low strata

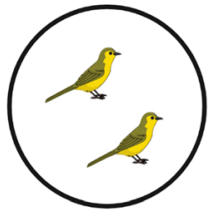

A. No sexual dimorphism

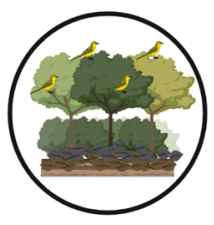

B. High strata

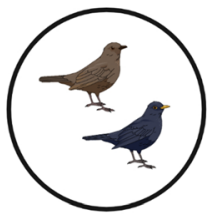

B. Sexual dimorphism

Individual level factors

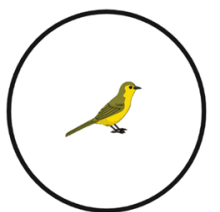

A. Smaller birds

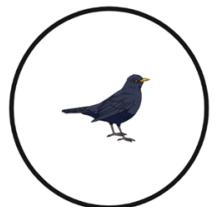

B. Larger birds

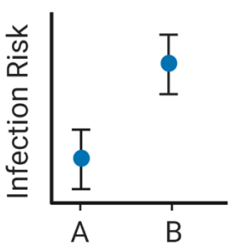

Plasmodium

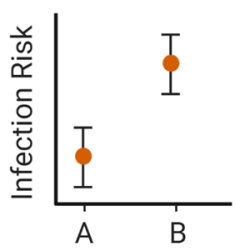

- Haemoproteus

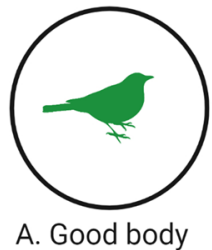

condition

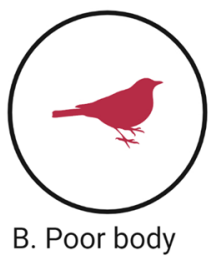

condition

Fig. 2 Predictions for the expected effects of different host ecological traits at the species-level and individual-level on infection risk by Plasmodium and Haemoproteus parasites. Plots show hypothetical relationships between infection risk (Plasmodium, blue and Haemoproteus, orange) and each level (A and B) of a particular ecological predictor; common plots shown for two ecologcial predictors on each row

variance-covariance matrix of phylogenetic distances between host species generated from the host phylogeny as a random effect. We used host phylogeny based on cytochrome $b$ sequence data (1143 bp) from earlier studies $[32,58]$. We included sampling sites as another random effect to account for non-independence among the sampled individuals due to sampling design. We conducted two separate BPMM analyses with the host species ecological traits and individual trait data because we had complete morphometric measurements for only a subset of individuals ( $n=991$ individuals). We excluded all individuals without complete information from the individual level BPMM analysis.

For both datasets, we first tested a fully parameterized model including all predictors and then ran subsequent reduced models by excluding non-significant predictors, one at a time based on $P$-values. We used weak, uninformative prior (normal distribution with mean of zero and very large variance) for the fixed effects, an expanded prior $\left(\chi^{2}\right.$ distribution with 1 degree of freedom) for the random effects and fixed residual variance at 1 , based on recommendations by de Villemereuil et al. [73] and
Hadfield [71]. We ran each model chain for 2 million iterations with burn-in of 100,000 and thinning intervals of 1000 iterations. Additionally, we conducted three independent MCMC runs for our final reduced model that included significant predictors from both speciesand individual-level analyses. Analyses for each parasite genus (Plasmodium and Haemoproteus) were conducted separately.

We visually analyzed the trace plots for all model parameters to assess mixing properties and stationarity of chains. We assessed convergence of the MCMC chains by evaluating correlation between samples (autocorrelation < 0.1) and Gelman-Rubin statistic (potential scale reduction factor, PSRF $<1.1$ preferred among chains) using R-package coda [74]. We considered model parameters to be significant when the $95 \%$ credible intervals (CIs) of posterior estimates excluded zero and $P$-values were $<0.05$. We evaluated the performance of our final reduced models using a suite of standard metrics including sensitivity, specificity, and area under the receiver-operator curve (AUC) statistic, as implemented in the R-package cutpointr. We also calculated predicted 
infection probabilities for each species and evaluated the model fits by plotting the observed and predicted infection probabilities.

Furthermore, we calculated the proportion of the total variance explained by host species phylogeny by estimating phylogenetic heritability, equivalent to Pagel's lambda $(\lambda)$ to measure the degree of phylogenetic signal $[75,76]$. We estimated the mean and $95 \%$ highest posterior density (HPD) of $\lambda$ for each MCMC chain by dividing the phylogenetic variance-covariance $(\mathrm{VCV})$ matrix by the sum of the phylogenetic, location, and residual VCV matrices [76]. All statistical analyses and graphing were conducted in R ver. 3.6.2 [77].

\section{Results}

\section{Avian haemosporidian prevalence}

Our dataset included 1177 birds across 28 bird species, representing almost the entire Shola Sky Island bird community (Additional file 1: Table S1). We found 24/28 bird species infected (490 birds, 41.6\% prevalence) with avian haemosporidians. Among the 47 unique haemosporidian lineages, 10/18 Plasmodium and 24/29 Haemoproteus lineages were novel and endemic to the Shola Sky Islands [32]. Haemosporidian prevalence varied across host species, with Turdus merula exhibiting high Plasmodium prevalence $(29 \%, n=86)$ and Zosterops palpebrosus showing high Haemoproteus prevalence $(77.1 \%, n=$ 118). The evaluation metrics revealed that final reduced models fit the data well in the case of both Plasmodium (sensitivity $=0.788$; specificity $=0.842$; AUC $=0.874$; Additional file 1: Table S4) and Haemoproteus (sensitivity $=0.889$; specificity $=0.709$; $\mathrm{AUC}=0.869$; Additional file 1: Table S4) parasites. We also observed a strong association between the observed infection probability and predicted infection probability for each species across both genera (Plasmodium, $R^{2}=0.88, P<0.001$; Haemoproteus, $R^{2}=0.95, P<0.001$ ), suggesting that our sampling was adequate to capture the true prevalence for each species (Additional file 1: Figure S1).

\section{Species ecology and individual body condition affects avian haemosporidian prevalence}

Some ecological predictors that we tested were unimportant for infection status responses (i.e. the 95\% CI overlapped with 0 ) and were removed to construct the reduced models (Additional file 1: Table S3). As expected, different ecological predictors were important for variation in infection risk by Plasmodium and Haemoproteus. At the species level, sociality and sexual dimorphism were positively associated with Plasmodium prevalence $(\beta=2.56$, CI: $0.30-5.06$; OR: 10.6$)$ and $(\beta=3.11$, CI: 0.84-5.19; OR: 20.1), respectively (Fig. 3a). Additionally, species foraging at high strata had lower Plasmodium prevalence $(\beta=-3.29$, CI: $-5.07--1.45$; OR: 0.03) compared to low strata foragers. For Haemoproteus, sociality and species elevation were significant predictors of Haemoproteus parasite prevalence in the Shola Sky Island bird community (Fig. 3b, Additional file 1: Table S3). Social roosting species had higher Haemoproteus prevalence ( $\beta=5.91$, CI: 3.26-8.67; OR: 315.5) compared to non-social species. The exceptionally high odds ratio for social $v s$ non-social species is interesting and reflects the large observed difference in parasite prevalence between these two groups $(0.53 \%$ and $0.13 \%$, respectively). Minimum elevation of host species had a significant positive association with Haemoproteus prevalence $(\beta=0.17$, CI: 0.01-0.34; OR: 1.22).

Among the individual level predictors, we did not find significant relationship between the various morphometric traits (tarsus and wing lengths), fluctuating asymmetry, body condition and variation in haemosporidian prevalence for Plasmodium parasites. But our final model for Haemoproteus revealed individual body condition as a significant predictor for Haemoproteus prevalence (Fig. 3b, Additional file 1: Table S3). Surprisingly, Haemoproteus prevalence increased significantly with birds having better body condition ( $\beta=0.59$, CI: $0.07-1.12$; OR: 1.87). All other predictors revealed no significant relationship with Haemoproteus parasite prevalence.

\section{Phylogenetic signal}

We recovered phylogenetic signal in both our full and reduced models, in the case of both Plasmodium and Haemoproteus; however, phylogenetic signal was lower for Plasmodium compared to Haemoproteus. After taking into account the variation explained by host ecological traits, location effects and residual variance, host species phylogeny explained $27 \%(\beta=4.78$, CI: $1.29-8.95)$ of the total variation observed in Plasmodium prevalence and $48 \%$ ( $\beta=10.97$, CI: $5.14-18.42)$ of the total variation in Haemoproteus prevalence across host species (Fig. 4, Additional file 1: Table S5).

\section{Discussion}

In this study, we show that multiple host ecological factors are important determinants of haemosporidian infection risk across avian hosts in the Western Ghats Sky Island bird community. However, these effects varied among Plasmodium and Haemoproteus parasites, likely due to their eco-evolutionary differences and vector preferences. Previous studies have also reported mixed support for the ability of host ecological factors to predict avian haemosporidian prevalence $[14,43,48$, 51]. This suggests that these patterns are far from universal and underlying host community structure influencing parasite exposure and/or host evolutionary history 
influencing host susceptibility likely plays a key role in assessing avian haemosporidian infection risk.

We hypothesized that prevalence of Haemoproteus parasites will increase with species' elevation as cooler temperatures at higher elevations may support the survival and development of both Haemoproteus parasites and their associated vectors (i.e. biting midges [78]). We lend support to this hypothesis as our results show that species elevation was significantly associated with Haemoproteus prevalence, with species at higher minimum elevation having higher Haemoproteus prevalence compared to species at lower minimum elevation. This agrees with previous studies that had found support for higher Haemoproteus prevalence at higher elevations with low temperatures $[43,79,80]$. In the light of global climate change, our findings indicate that Haemoproteus parasites, which are currently more prevalent at higher elevations, might undergo range collapse due to unavailability of suitable environment (niche) for its survival and development [81]. In addition to the environmental constraints on Haemoproteus parasites, the observed patterns could also be confounded by specific host species present at high elevation as Haemoproteus parasites tend to be host specialists in the Western Ghats [32].

Our findings indicate that host species ecological traits that promote exposure risk likely explain the increased prevalence of avian haemosporidian parasites. Several studies have found evidence for higher avian haemosporidian prevalence in social birds [45], but see Arriero \& Moller [15]. Among the various host ecological traits tested in our study, we found sociality as a consistent and an important explanatory variable, positively associated with prevalence of both Plasmodium and Haemoproteus. Sociality may increase the probability of hosts encountering vectors thereby promoting parasite transmission [6]. It has been hypothesized that higher aggregation of vectors may occur around social species as host-seeking behavior of malaria vectors relies on the odor cues $\left(\mathrm{CO}_{2}\right)$ and chemical attractants released by the host species [82]. This may explain higher prevalence of avian haemosporidians among social species in the Western Ghats Sky Island bird communities.

While there was no significant association between Haemoproteus prevalence and foraging strata of host species, species foraging at high strata (canopy level) exhibited lower Plasmodium prevalence compared to species at the ground level. Vertical stratification in arthropod vectors that influence hosts' exposure risk could drive this variation in Plasmodium prevalence due to differences in vector abundance. Vectors for Plasmodium (Culex spp. and Aedes spp.) are known to preferentially feed at the ground-level $[46,47,83]$, thus reducing their abundance at the canopy level. However, our findings contrast with other studies that showed higher Plasmodium prevalence for middle- to high-level foragers [84] and low for ground foragers [85]. Although we could not yet directly assess the role of vectors in transmitting
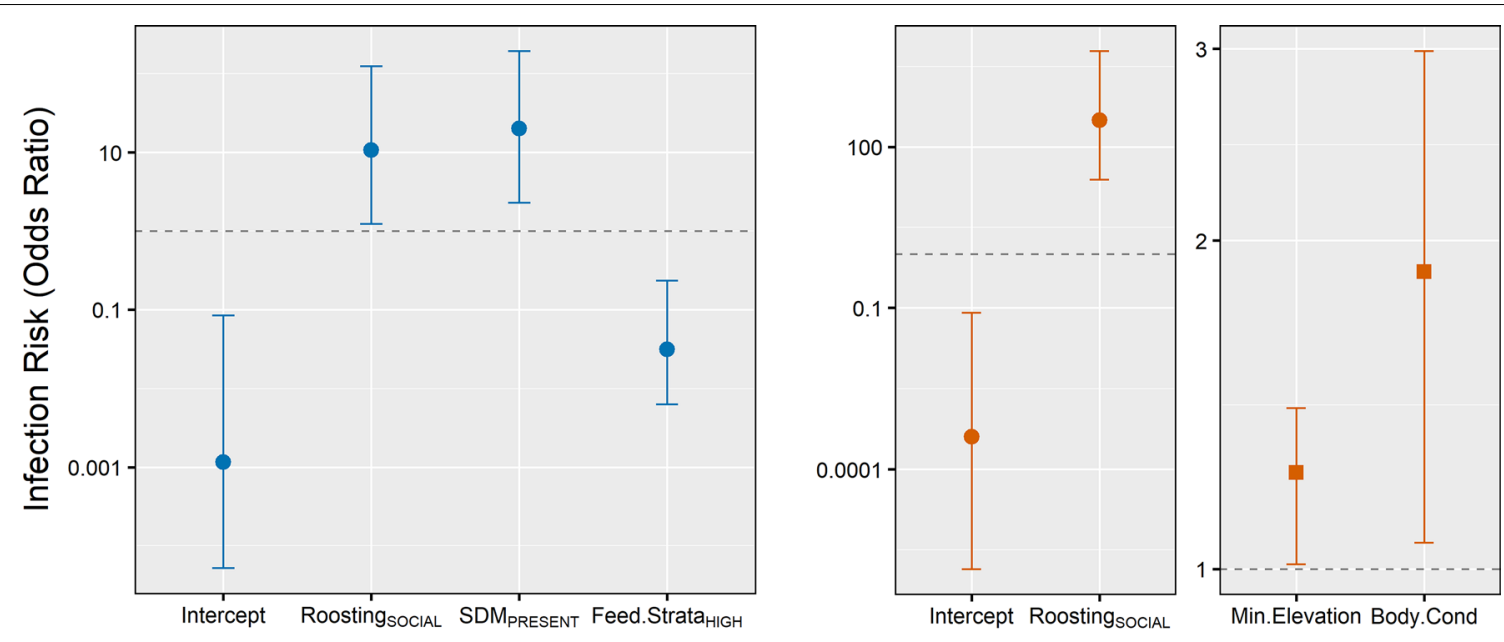

\section{Ecological predictors}

Fig. 3 The effect of host ecological predictors on avian haemosporidian infection risk in the Western Ghats Sky Islands. Results of our final reduced Bayesian phylogenetic mixed model with posterior mean estimates and $95 \%$ credible intervals (Cls) of all significant predictors on infection risk by Plasmodium (a) and Haemoproteus (b). Model parameters were considered significant when the $95 \%$ Cls of posterior estimates excluded zero. Categorical variables tested include roosting behavior (non-social vs social), sexual dimorphism (absent vs present), feeding strata (low vs high), with the former as the reference category and two covariates: species minimum elevation and individual body condition (scaled mass index) 


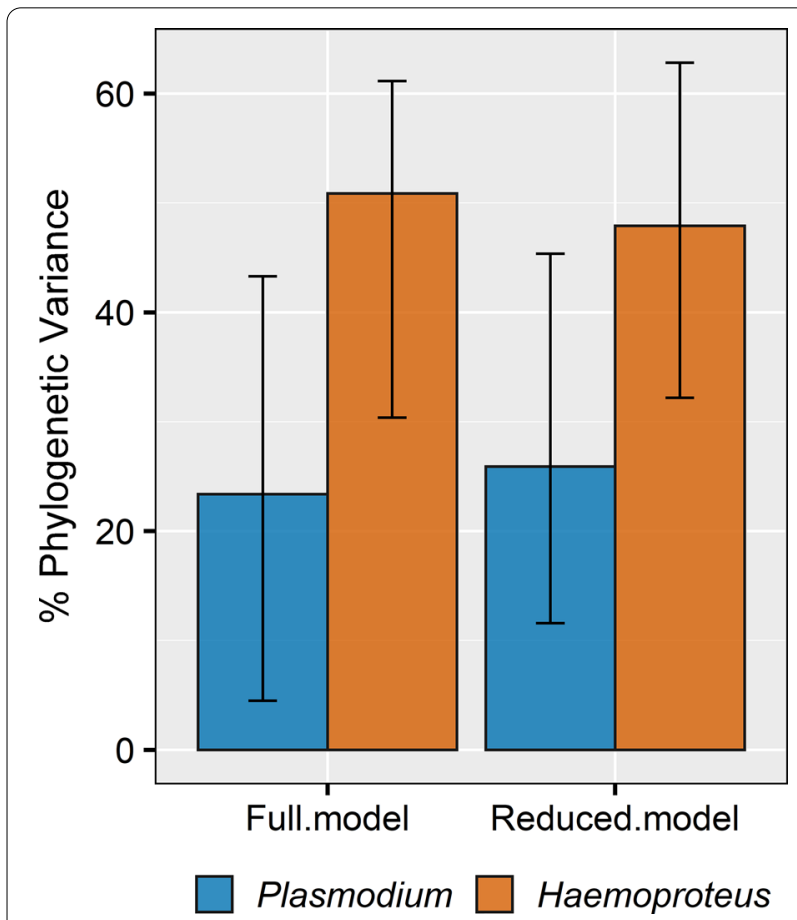

Fig. 4 Proportion of total variance attributed to host species phylogeny representing phylogenetic signal or lambda (k). Reported are the percent posterior means and 95\% credible intervals across full and reduced Bayesian phylogenetic mixed models estimated in MCMCgImm, shown for Plasmodium (blue) and Haemoproteus (orange)

avian haemosporidian parasites in the Western Ghats, we propose integrating information on the distribution and abundance of mosquitoes and biting midges in future research will be invaluable and help resolve these conflicting patterns.

Inter-specific variation in avian haemosporidian prevalence may also result from differences in host susceptibility to infection. Host susceptibility can vary among hosts due to host traits or differences in host-parasite coevolutionary histories [86]. As expected, we found levels of sexual dimorphism were positively associated with Plasmodium infection risk, as has been reported in previous studies [85, 87]. This pattern of sexual dimorphism affecting haemosporidian infection lends support to Hamilton and Zuk's hypothesis [50], whereby sexual selection favors costly male phenotypic traits (e.g. plumage brightness) as indicators of parasite resistance. Thus, higher levels of sexual dimorphism among species tends to be associated with higher parasite infection [49].

With individual body condition, we expected to find low probability of infection in birds with better condition because generally, parasitic infections negatively affect host body condition [20, 27, 88]. Hosts in poor body condition are likely more susceptible to infection due to reduced immunocompetence $[4,89,90]$. Contrary to our expectations, we found no significant association between host body condition and Plasmodium infection and a positive effect of body condition on the probability of Haemoproteus infection. Birds with better body condition had higher Haemoproteus infection compared to birds in poorer body condition. Although parasites are generally thought to be detrimental to their hosts, parasites may not always be harmful to their hosts and hosts in good body condition can often tolerate higher parasite loads, leading to a positive relationship between body condition and infection status [20,91]. Our findings suggest that birds were likely tolerant to Haemoproteus infection and did not suffer high costs to infection and or at least to the extent that it is not reflected in their body condition. However, parasitemia data and other fitness measures (e.g. reproductive success) are needed to confirm our findings of fitness costs and the underlying host defense mechanisms in response to avian haemosporidian infection in the Western Ghats. Understanding the relative investment in resistance $v s$ tolerance is critical, as it can affect disease dynamics at both individual- and species-level [92]. For example, highly tolerant individuals could be more efficient at transmitting disease in a population (i.e. super-spreaders [93]). Additionally, host species that are tolerant to parasite infection may serve as reservoirs of infection and represent an indirect threat to more vulnerable host species, as has been shown in other host-parasite systems (e.g. [94-96]), an issue critical for conservation of threatened host species.

We found higher phylogenetic signal in Haemoproteus compared to Plasmodium, indicating phylogenetic conservatism of host susceptibility to infection. Host phylogenetic relationships could be important in shaping patterns of parasite prevalence and disease transmission because closely related hosts are similar in their behavioral, physiological and immunological characteristics [97]. Consequently, several studies have shown that closely related hosts share more similar parasite communities and host phylogenetic distance is a key predictor of cross-species transmission [98-100], thus, increasing the likelihood for emergence of infectious diseases. Our results on infection dynamics support findings from a previous genetic study which showed that Haemoproteus have high phylogenetic host specificity and closely related host species tend to share similar Haemoproteus lineages compared to Plasmodium, a relatively generalist parasite [32]. Although the magnitude of effect differs between the two parasite genera, we demonstrate that host ecological traits and host evolutionary history are both important factors in explaining interspecific variation in avian haemosporidian infection risk. It is possible that constraints on the distribution of these parasites 
are likely more related to their avian hosts (not vectors) within the Western Ghats Sky Island bird community. However, a better understanding of the relative importance of ecology of bird hosts and vectors of avian haemosporidians in the Western Ghats will be an important next step to better understand and predict patterns of infection risk for these vector-borne parasites.

\section{Conclusions}

Taken together, we found strong support for the role of host ecological traits and host phylogenetic relationships in influencing variation in avian haemosporidian risk in the Western Ghats Sky Island bird community. As hypothesized, the relative importance of these effects varied among the two avian haemosporidian genera, Plasmodium and Haemoproteus. Our analyses of various ecological factors suggest that variation in avian haemosporidian infection risk is likely driven by two underlying mechanisms. First, ecological factors (e.g. sociality, foraging strata) that may lead to differential exposure risk could impact avian haemosporidian prevalence. Secondly, ecological factors associated with disease susceptibility or tolerance (e.g. sexual dimorphism, body condition) to infection are important predictors of avian haemosporidian prevalence. To better understand the effect of host ecological factors, research needs to account for host phylogenetic relationships in driving susceptibility to infection and subsequent disease transmission. In this study, we demonstrate the importance of host phylogenetic relationships in influencing variation in infection risk to avian haemosporidians, which is consistent with previous work by Barrow et al. [54]. Higher magnitude of phylogenetic signal in the case of Haemoproteus compared to Plasmodium parasites tends to be coherent with their host specificity patterns in our community [32]. We conclude that patterns of avian haemosporidian prevalence and infection risk were shaped by joint contributions of both host ecology and host evolutionary history. Understanding host-parasite interactions in a broader eco-evolutionary context, including host phylogenetic relatedness is critical to gain a better understanding of drivers of interspecific variation in infection risk. Ultimately, such efforts could help illuminate the idiosyncratic association between host ecological traits and infection risk, help identify key reservoir hosts and enable improved predictions of infection risk in multi-host communities. Although we focused on avian haemosporidian parasites, this study helps to better understand vector-borne disease dynamics, and particularly improves our understanding of how disease transmission is linked to host behavior (e.g. sociality), physiology (e.g. body condition) and other parameters associated with disease susceptibility (e.g. host evolutionary history). Our results contribute to a growing body of evidence from other vector-borne diseases (e.g. West Nile virus infection and/or Lyme disease) that highlight the importance of host species heterogeneity in disease transmission dynamics [3, 101]. Finally, our work presents an important step towards identifying and understanding variation in infection risk at the individual- and species-level in an important biodiversity hotspot. Elucidating the ecological and evolutionary drivers that contribute to host heterogeneity in infection risk and potential spillover risk to naïve hosts will be important from wildlife health and conservation perspective as the number and severity of emerging infections increase globally.

\section{Supplementary information}

Supplementary information accompanies this paper at https://doi. org/10.1186/s13071-020-04404-8.

Additional file 1: Table S1. Details on the ecological traits for each avian host species sampled from the Shola Sky Island bird community in the Western Ghats. Table S2. Detailed methods for calculation of specific ecological and morphological variables used in the Bayesian phylogenetic mixed model (MCMCglmm analysis). Table S3. Summary of results for Bayesian phylogenetic mixed models (MCMCglmm analysis) with parasite infection status as the response variable and various host ecological and morphological traits as the predictor variables. Table S4. Summary of model evaluation metrics calculated by comparing the observed and predicted data. Table $\mathbf{S 5}$. Phylogenetic signal or lambda ( $k$ ) estimates from MCMCglmm for full and reduced models for Plasmodium and Haemoproteus, calculated as the proportion of total variance attributed to phylogenetic variance. Figure S1. Fit between the observed and predicted probabilities of haemosporidian infection for each bird species.

\section{Acknowledgements}

We thank the Forest Departments of Kerala, particularly then PCCFs (R. Rajaraja Varma, V. Gopinathan, T. M. Manoharan and B. S. Corrie) and Tamil Nadu (R. Sunderaraju) for bird sampling permits. We also thank all the CCFs, Wildlife Wardens, DFOs and rangers who helped us with the logistics of field work in these remote locations. All laboratory work associated with this study was carried out in the laboratory of Uma Ramakrishnan, National Centre for Biological Sciences, Bangalore, and we thank her for the use of these facilities. Figures in the manuscript were created in Mind the Graph and Biorender platforms.

\section{Authors' contributions}

PG, VVR and GD conceived and designed the study. CKV and VR coordinated and collected field data. PG conducted molecular laboratory work, performed data analyses with help from GD, and prepared first draft of the manuscript. PG, CKV, VVR and GD revised and edited the manuscript. All authors read and approved the final manuscript.

\section{Funding}

Financial support was provided from the U.S. Department of Energy Financial Assistance Award no. DE-EM0004391 to the University of Georgia Research Foundation. This work also was funded by Ramanujan Fellowship from Department of Science and Technology, India to GD, National Geographic Society Research and Exploration grant to WVR.

Availability of data and materials

All data generated or analyzed during this study are included in this published article and its additional files. 


\section{Ethics approval and consent to participate}

This study was carried out in accordance with bird sampling permits granted by the Forest Departments of Kerala and Tamil Nadu, and institutional animal ethics clearance from the National Centre for Biological Sciences, Bangalore, India.

\section{Consent for publication}

Not applicable.

\section{Competing interests}

The authors declare that they have no competing interests.

\section{Author details}

${ }^{1}$ Savannah River Ecology Laboratory, University of Georgia, Aiken, SC, USA.

${ }^{2}$ Warnell School of Forestry and Natural Resources, University of Georgia, Athens, GA 30602, USA. ${ }^{3}$ Indian Institute of Science Education and Research Kolkata, Mohanpur, West Bengal 741246, India. ${ }^{4}$ Indian Institute of Science Education and Research Tirupati, Mangalam, Tirupati 517507, India.

Received: 1 June 2020 Accepted: 14 October 2020

Published online: 28 October 2020

\section{References}

1. Smith KF, Acevedo-Whitehouse K, Pedersen AB. The role of infectious diseases in biological conservation. Anim Conserv. 2009;12:1-12.

2. Gupta P, Robin W, Dharmarajan G. Towards a more healthy conservation paradigm: integrating disease and molecular ecology to aid biological conservation. J Genet. 2020;99:1-26.

3. Kilpatrick AM, Daszak P, Jones MJ, Marra PP, Kramer LD. Host heterogeneity dominates West Nile virus transmission. Proc R Soc B Biol Sci. 2006;273:2327-33.

4. Beldomenico PM, Begon M. Disease spread, susceptibility and infection intensity: vicious circles? Trends Ecol Evol. 2010:25:21-7.

5. Barron DG, Gervasi SS, Pruitt JN, Martin LB. Behavioral competence: How host behaviors can interact to influence parasite transmission risk. Curr Opin Behav Sci. 2015;6:35-40

6. Ezenwa VO, Ghai RR, McKay AF, Williams AE. Group living and pathogen infection revisited. Curr Opin Behav Sci. 2016;12:66-72.

7. Parham PE, Waldock J, Christophides GK, Hemming D, Agusto F, Evans $\mathrm{KJ}$, et al. Climate, environmental and socio-economic change: weighing up the balance in vector-borne disease transmission. Philos Trans R Soc B. 2015;370:20130551.

8. Johnson PTJ, Rohr JR, Hoverman JT, Kellermanns E, Bowerman J, Lunde KB. Living fast and dying of infection: Host life history drives interspecific variation in infection and disease risk. Ecol Lett. 2012;15:235-42.

9. Gutiérrez JS, Piersma T, Thieltges DW. Micro- and macroparasite species richness in birds: the role of host life history and ecology. J Anim Ecol. 2019:88:1226-39.

10. Altizer S, Nunn CL, Thrall PH, Gittleman JL, Antonovics J, Cunningham AA, et al. Social organization and parasite risk in mammals: Integrating theory and empirical studies. Annu Rev Ecol Evol Syst. 2003;34:517-47.

11. Medeiros MCl, Ricklefs RE, Brawn JD, Hamer GL. Plasmodium prevalence across avian host species is positively associated with exposure to mosquito vectors. Parasitology. 2015;142:1612-20.

12. LaPointe DA, Goff ML, Atkinson CT. Thermal constraints to the sporogonic development and altitudinal distribution of avian malaria Plasmodium relictum in Hawai'i. J Parasitol. 2010;96:318-24.

13. Garvin MC, Remsen JV. An alternative hypothesis for heavier parasite loads of brightly colored birds: Exposure at the nest. Auk. 1997;114:179-91.

14. González AD, Matta NE, Ellis VA, Miller ET, Ricklefs RE, Gutiérrez HR. Mixed species flock, nest height, and elevation partially explain avian haemoparasite prevalence in Colombia. PLoS One. 2014;9:e100695.

15. Arriero E, Moller AP. Host ecology and life-history traits associated with blood parasite species richness in birds. J Evol Biol. 2008;21:1504-13.

16. Fecchio A, Lima MR, Silveira P, Braga ÉM, Marini M. High prevalence of blood parasites in social birds from a Neotropical savanna in Brazil. Emu. 2011;111:132.
17. Moller AP. Parasites differentially increase the degree of fluctuating asymmetry in secondary sexual characters. J Evol Biol. 1992;5:691-9.

18. Beasley DAE, Bonisoli-Alquati A, Mousseau TA. The use of fluctuating asymmetry as a measure of environmentally induced developmental instability: a meta-analysis. Ecol Indic. 2013;30:218-26.

19. Merino S, Hennicke J, Martínez J, Ludynia K, Torres R, Work TM, et al. Infection by Haemoproteus parasites in four species of frigatebirds and the description of a new species of Haemoproteus (Haemosporida: Haemoproteidae). J Parasitol. 2012;98:388-97.

20. Sánchez CA, Becker DJ, Teitelbaum CS, Barriga P, Brown LM, Majewska $A A$, et al. On the relationship between body condition and parasite infection in wildlife: a review and meta-analysis. Ecol Lett. 2018:21:1869-84.

21. Valkiŭnas G. Avian malaria parasites and other haemosporidia. New York: CRC Press; 2005.

22. Bensch S, Hellgren O, Perez-Tris J. MalAvi: a public database of malaria parasites and related haemosporidians in avian hosts based on mitochondrial cytochrome b lineages. Mol Ecol Resour. 2009:9:1353-8.

23. Santiago-Alarcon D, Palinauskas V, Schaefer HM. Diptera vectors of avian haemosporidian parasites: untangling parasite life cycles and their taxonomy. Biol Rev Camb Philos Soc. 2012;87:928-64.

24. Asghar M, Dennis H, Bengt H, Pavel Z, Helena W, Staffan B. Hidden costs of infection: chronic malaria accelerates telomere degradation and senescence in wild birds. Science. 2015;347:9-12.

25. Lachish S, Knowles SCL, Alves R, Wood MJ, Sheldon BC. Fitness effects of endemic malaria infections in a wild bird population: the importance of ecological structure. J Anim Ecol. 2011;80:1196-206.

26. Asghar M, Hasselquist D, Bensch S. Are chronic avian haemosporidian infections costly in wild birds? J Avian Biol. 2011;42:530-7.

27. Schrader MS, Walters EL, James FC, Greiner EC. Seasonal prevalence of a haematozoan parasite of red-bellied woodpeckers (Melanerpes carolinus) and its association with host condition and overwinter survival. Auk. 2003;120:130-7.

28. Levin II, Outlaw DC, Vargas FH, Parker PG. Plasmodium blood parasite found in endangered Galapagos penguins (Spheniscus mendiculus). Biol Conserv. 2009:142:3191-5.

29. Atkinson CT, Samuel MD. Avian malaria Plasmodium relictum in native Hawaiian forest birds: epizootiology and demographic impacts on àapapane Himatione sanguinea. J Avian Biol. 2010;41:357-66.

30. Argilla LS, Howe L, D GB, Alley MR. High prevalence of Leucocytozoon spp. in the endangered yellow-eyed penguin (Megadyptes antipodes) in the sub-Antarctic regions of New Zealand. Parasitology. 2013;140:672-82

31. Dadam D, Robinson RA, Clements A, Peach WJ, Bennett M, Rowcliffe JM, et al. Avian malaria-mediated population decline of a widespread iconic bird species. R Soc Open Sci. 2019;6:182197.

32. Gupta P, Vishnudas CK, Ramakrishnan U, Robin VV, Dharmarajan G. Geographical and host species barriers differentially affect generalist and specialist parasite community structure in a tropical sky-island archipelago. Proc R Soc B. 2019;286.

33. Clark NJ, Clegg SM, Lima MR. A review of global diversity in avian hae mosporidians (Plasmodium and Haemoproteus: Haemosporida): new insights from molecular data. Int J Parasitol. 2014:44:329-38.

34. Beadell JS, Covas R, Gebhard C, Ishtiaq F, Melo M, Schmidt BK, et al. Host associations and evolutionary relationships of avian blood parasites from West Africa. Int J Parasitol. 2009;39:257-66.

35. Fecchio A, Wells K, Bell JA, Tkach VV, Lutz HL, Weckstein JD, et al. Climate variation influences host specificity in avian malaria parasites. Ecol Lett. 2019;22:547-57.

36. Moens MAJ, Pérez-Tris J. Discovering potential sources of emerging pathogens: South America is a reservoir of generalist avian blood parasites. Int J Parasitol. 2016:46:41-9.

37. Fecchio A, Pinheiro R, Felix G, Faria IP, Pinho JB, Lacorte GA, et al. Host community similarity and geography shape the diversity and distribution of haemosporidian parasites in Amazonian birds. Ecography. 2017:41:505-15.

38. Olsson-Pons S, Clark NJ, Ishtiaq F, Clegg SM. Differences in host species relationships and biogeographic influences produce contrasting patterns of prevalence, community composition and genetic structure in two genera of avian malaria parasites in southern Melanesia. J Anim Ecol. 2015:84:985-98. 
39. Fallon SM, Bermingham E, Ricklefs RE. Host specialization and geographic localization of avian malaria parasites: a regional analysis in the Lesser Antilles. Am Nat. 2005;165:466-80.

40. Scordato ESC, Kardish MR. Prevalence and beta diversity in avian malaria communities: Host species is a better predictor than geography. J Anim Ecol. 2014;83:1387-97.

41. Zamora-Vilchis I, Williams SE, Johnson CN. Environmental temperature affects prevalence of blood parasites of birds on an elevation gradient: implications for disease in a warming climate. PLoS One. 2012;7:e39208.

42. Van Rooyen J, Lalubin F, Glaizot O, Christe P, van Rooyen J, Lalubin F, et al. Altitudinal variation in haemosporidian parasite distribution in great tit populations. Parasit Vectors. 2013;6:1-10.

43. Illera JC, Padilla LG, Lopez G, Angel M. Factors governing the prevalence and richness of avian haemosporidian communities within and between temperate mountains. PLoS One. 2017;12:1-22.

44. Jones MR, Cheviron ZA, Carling MD. Spatial patterns of avian malaria prevalence in Zonotrichia capensis on the Western slope of the Peruvian Andes. J Parasitol. 2013;99:903-5.

45. Tella JL. The evolutionary transition to coloniality promotes higher blood parasitism in birds. 2002;15:32-41.

46. Cerny O, Votypka J, Svobodova M. Spatial feeding preferences of ornithophilic mosquitoes, blackflies and biting midges. Med Vet Entomol. 2011;25:104-8

47. Garvin MC, Greiner EC. Ecology of Culicoides (Diptera: Ceratopogonidae) in southcentral Florida and experimental culicoides vectors of the avian hematozoan Haemoproteus danilewskyi kruse. J Wildl Dis. 2003;39:170-8.

48. Lutz HL, Hochachka WM, Engel Jl, Bell JA, Tkach W, Bates JM, et al. Parasite prevalence corresponds to host life history in a diverse assemblage of Afrotropical birds and haemosporidian parasites. PLoS One. 2015;10:1-24.

49. Moller AP. Parasites and sexual selection: current status of the Hamilton and Zuk hypothesis. J Evol Biol. 1990;3:319-28.

50. Hamilton WD, Zuk M. Heritable true fitness and bright birds : a role for parasites? Science. 1982;218:384-7.

51. Scheuerlein A, Ricklefs RE. Prevalence of blood parasites in European passeriform birds. Proc R Soc London Ser B Biol Sci. 2004;271:1363-70.

52. Ludwig W. Das Rechts-Links-Problem im Tierreich und Beim Menschen. Berlin: Springer; 1932

53. Ricklefs RE, Swanson BL, Fallon SM, Martínez-Abraín A, Scheuerlein A, Gray J, et al. Community relationships of avian malaria parasites. Ecol Monogr. 2005;75:543-59.

54. Barrow LN, McNew SM, Mitchell N, Galen SC, Lutz HL, Skeen H, et al. Deeply conserved susceptibility in a multi-host, multi-parasite system. Ecol Lett. 2019;22:987-98.

55. Myers N, Mittermeler RA, Mittermeler CG, Da Fonseca GAB, Kent J. Biodiversity hotspots for conservation priorities. Nature. 2000;403:853-8.

56. Robin W, Nandini R. Shola habitats on Sky Islands: status of research on montane forests and grasslands in southern India. Curr Sci. 2012;103:1427-37.

57. Grogan LF, Berger L, Rose K, Grillo V, Cashins SD, Skerratt LF. Surveillance for emerging biodiversity diseases of wildlife. PLoS Pathog. 2014:10:e1004015.

58. Robin VV, Vishnudas CK, Gupta P, Ramakrishnan U. Deep and wide valleys drive nested phylogeographic patterns across a montane bird community. Proc R Soc B Biol Sci. 2015;282:20150861.

59. Vidya TNC, Fernando P, Melnick DJ, Sukumar R. Population differentiation within and among Asian elephant (Elephas maximus) populations in southern India. Heredity. 2005;94:71-80.

60. Vijayakumar SP, Menezes RC, Jayarajan A, Shanker K. Glaciations, gradients, and geography: multiple drivers of diversification of bush frogs in the Western Ghats Escarpment. Proc R Soc B Biol Sci. 2016;282:20161011.

61. Lapointe DA, Atkinson CT, Samuel MD. Ecology and conservation biology of avian malaria. Ann NY Acad Sci. 2012;1249:211-26.

62. Altizer S, Ostfeld RS, Johnson PTJ, Kutz S, Harvell CD. Climate change and infectious diseases: from evidence to a predictive framework. Science. 2013;341:514-9.

63. Robin W, Vishnudas CK, Ramakrishnan U. Reassessment of the distribution and threat status of the Western Ghats endemic bird. Nilgiri pipit Anthus nilghiriensis. Curr Sci. 2014;107:622-30.
64. Hellgren O, Waldenström J, Bensch S, Heligren O, Waldenstrom J, Bensch S, et al. A new PCR assay for simultaneous studies of Leucocytozoan, Plasmodium, and Haemoproteus from avian blood. J Parasitol. 2004;90:797-802.

65. Kearse M, Moir R, Wilson A, Stones-Havas S, Cheung M, Sturrock S, et al. Geneious Basic: an integrated and extendable desktop software platform for the organization and analysis of sequence data. Bioinformatics. 2012;28:1647-9.

66. Wilman H, Belmaker J, Simpson J, de la Rosa C, Rivadeneira MM, Jetz W. EltonTraits 1.0: species-level foraging attributes of the world's birds and mammals. Ecology. 2014;95:2027-2027

67. Somasundaram S, Vijayan L. Foraging behaviour and guild structure of birds in the montane wet temperate forest of the Palni Hills. South India. Podoces. 2008;3:79-91.

68. Ali S, Ripley SD. Compact handbook of the birds of India and Pakistan. 2nd ed. New Delhi: Oxford University Press; 1987.

69. Van Dongen S. Accuracy and power in the statistical analysis of fluctuating asymmetry: effects of between-individual heterogeneity in developmental instability. Ann Zool Fennici. 1999;36:45-52.

70. Peig J, Green AJ. New perspectives for estimating body condition from mass/length data: the scaled mass index as an alternative method. Oikos. 2009;118:1883-91.

71. Hadfield JD. MCMC methods for multi-response generalized linear mixed models: the MCMCglmm R package. J Stat Softw. 2010;33:1-22.

72. Garamszegi L. Modern phylogenetic comparative methods and their application in evolutionary biology: concepts and practice. Berlin: Springer; 2014

73. de Villemereuil P, Gimenez O, Doligez B. Comparing parent-offspring regression with frequentist and Bayesian animal models to estimate heritability in wild populations: a simulation study for Gaussian and binary traits. Methods Ecol Evol. 2013:4:260-75.

74. Plummer M, Best N, Cowles K, Vines K. CODA: convergence diagnosis and output analysis for MCMC. R News. 2006;6:7-11.

75. Pagel M. Inferring the historical patterns of biological evolution. Nature. 1999:401:877-84.

76. Hadfield JD, Nakagawa S. General quantitative genetic methods for comparative biology: phylogenies, taxonomies and multi-trait models for continuous and categorical characters. J Evol Biol. 2010;23:494-508.

77. R Core Team. R: A language and environment for statistical computing. Vienna, Austria: R Foundation for Statistical Computing; 2019. URL http//www.R-project.org/.

78. Berenger J-M, Parola P. Arthropod vectors of medical importance. Infect Dis (Auckl). 4th ed. Amsterdam: Elsevier; 2016. p. 104-12.

79. Pérez-Rodríguez A, Fernández-González S, de la Hera I, Pérez-Tris J. Finding the appropriate variables to model the distribution of vectorborne parasites with different environmental preferences: climate is not enough. Glob Chang Biol. 2013;19:3245-53.

80. Harrigan RJ, Sedano R, Chasar AC, Chaves JA, Nguyen JT, Whitaker A, et al. New host and lineage diversity of avian haemosporidia in the northern Andes. Evol Appl. 2014;7:799-811.

81. Pérez-Rodríguez A, de la Hera I, Fernández-González S, Pérez-Tris J. Global warming will reshuffle the areas of high prevalence and richness of three genera of avian blood parasites. Glob Chang Biol. 2014;20:2406-16

82. Lehane MJ. The biology of blood-sucking in insects. 2nd ed. New York: Cambridge University Press; 2005.

83. Mellor PS, Boorman J, Baylis M. Culicoides biting midges: their role as arbovirus vectors. Annu Rev Entomol. 2000;45:307-40.

84. Astudillo VG, Hernández SM, Kistler WM, Boone SL, Lipp EK, Shrestha S, et al. Spatial, temporal, molecular, and intraspecific differences of haemoparasite infection and relevant selected physiological parameters of wild birds in Georgia, USA. Int J Parasitol Parasites Wildl. 2013:2:178-89.

85. Svensson-coelho M, Blake JG, Loiselle BA, Penrose AS, Parker PG, Ricklefs RE. Diversity, prevalence, and host specificity of avian Plasmodium and Haemoproteus in a Western Amazon assemblage. Ornithol Monogr. 2013;76:1-47.

86. Medeiros $\mathrm{MCl}$, Hamer GL, Ricklefs RE. Host compatibility rather than vector-host-encounter rate determines the host range of avian Plasmodium parasites. Proc Biol Sci. 2013;280:20122947.

87. Scheuerlein A, Ricklefs RE. Prevalence of blood parasites in European passeriform birds. Proc R Soc B Biol Sci. 2004:271:1363-70. 
88. Møller AP, Christe P, Erritzøe J, Mavarez J, Moller AP, Erritzoe J. Condition, disease and immune defence. Oikos. 1998;83:301.

89. Merrill L, Levengood JM, England JC, Osborn JM, Hagy HM. Blood parasite infection linked to condition of spring-migrating Lesser Scaup (Aythya affinis). Can J Zool. 2018;96:1145-52.

90. Flint PL, Franson JC. Does influenza A affect body condition of wild mallard ducks, or vice versa? Proc R Soc B Biol Sci. 2009;276:2345-6.

91. Budischak SA, O'Neal D, Jolles AE, Ezenwa VO. Differential host responses to parasitism shape divergent fitness costs of infection. Funct Ecol. 2018;32:324-33.

92. Dharmarajan G, Walker KD, Lehmann T. Variation in tolerance to parasites affects vectorial capacity of natural Asian tiger mosquito populations. Curr Biol. 2019;29:3946-52.

93. Gopinath S, Lichtman JS, Bouley DM, Elias JE, Monack DM. Role of disease-associated tolerance in infectious superspreaders. Proc Natl Acad Sci USA. 2014;111:15780-5.

94. Adelman JS, Kirkpatrick L, Grodio JL, Hawley DM. House finch populations differ in early inflammatory signaling and pathogen tolerance at the peak of Mycoplasma gallisepticum infection. Am Nat. 2013:181:674-89.

95. Atkinson CT, Saili KS, Utzurrum RB, Jarvi SI. Experimental evidence for evolved tolerance to avian malaria in a wild population of low elevation Hawai'i ' amakihi (Hemignathus virens). Ecohealth. 2013;10:366-75.
96. Knutie SA, Owen JP, Mcnew SM, Bartlow AW, Arriero E, Herman JM, et al. Galapagos mockingbirds tolerate introduced parasites that affect Darwin's finches. Ecology. 2016;97:940-50.

97. Woolhouse MEJ, Haydon DT, Antia R. Emerging pathogens: the epidemiology and evolution of species jumps. Trends Ecol Evol. 2005;20:238-44.

98. Braga MP, Razzolini E, Boeger WA. Drivers of parasite sharing among Neotropical freshwater fishes. J Anim Ecol. 2015;84:487-97.

99. Longdon B, Hadfield JD, Webster CL, Obbard DJ, Jiggins FM. Host phylogeny determines viral persistence and replication in novel hosts. PLoS Pathog. 2011;7:e1002260.

100. Streicker DG, Turmelle AS, Vonhof MJ, Kuzmin IV, McCracken GF, Rupprecht CE. Host phylogeny constrains cross-species emergence and establishment of rabies virus in bats. Science. 2010;329:676-9.

101. LoGiudice K, Ostfeld RS, Schmidt KA, Keesing F. The ecology of infectious disease: effects of host diversity and community composition on Lyme disease risk. Proc Natl Acad Sci USA. 2003;100:567-71.

\section{Publisher's Note}

Springer Nature remains neutral with regard to jurisdictional claims in published maps and institutional affiliations.
Ready to submit your research? Choose BMC and benefit from:

- fast, convenient online submission

- thorough peer review by experienced researchers in your field

- rapid publication on acceptance

- support for research data, including large and complex data types

- gold Open Access which fosters wider collaboration and increased citations

- maximum visibility for your research: over 100M website views per year

At BMC, research is always in progress.

Learn more biomedcentral.com/submissions 